\title{
Fibrose cística em dois irmãos adultos em estado da Amazônia: estudo de caso
}

\author{
Cystic fibrosis in two adult siblings in the state of Amazonia: a case study
}

Fibrosis quística en dos hermanos adultos en estado de la Amazonia: estudio de caso

\author{
Maitê dos Santos Feitosa ${ }^{1 *}$, Maisa dos Santos Feitosa ${ }^{1}$, Jefison da Silva Lopes ${ }^{1}$, Dayanne Aline \\ Bezerra de Sá1, Nayara Henestyne Cantuária Figueiredo¹, Victor Hugo Monteiro Pontes ${ }^{1}$, Allan \\ Rowe da Gama1', Elza Rezende de Almeida²
}

\section{RESUMO}

Relato de caso: Paciente 01: 33 anos, apresentava desde a adolescência dispneia aos esforços, tosse e pneumonias. Adulto, evoluiu com piora da função pulmonar e hipersecreção, sendo diagnosticado com fibrose cística (FC) por dois testes do suor positivos. Apresentou intercorrência infecciosa, foi internado para realizar antibioticoterapia, durante a hospitalização apresentou insuficiência respiratória e choque, e após deterioração clínica evoluiu a óbito. Paciente 02: 32 anos, na infância apresentava tosse secretiva e dispneia aos esforços. Já adulto, os sintomas agravaram. Em consulta foi avaliado e diagnosticado com FC, através de teste do suor positivo. Segue estável com antibioticoterapia ocasional para exacerbações clínicas. A família apresentava histórico positivo para a doença, com um irmão e tia paterna já falecidos com diagnóstico e história clínica sugestiva, respectivamente. Discussão: Afirmando o caráter genético da FC, descreveu-se o relato de dois pacientes adultos e irmãos. A evolução da doença tem relação direta com a gravidade da doença pulmonar. Um paciente apresentava desnutrição, confirmando a grave insuficiência pancreática descrita na literatura. Estudos afirmam que a infertilidade é comum nos fibrocísticos, diferentemente dos pacientes deste estudo, que já possuem prole constituída. Um paciente faleceu durante o estudo, ratificando o prognóstico reservado da doença. O estudo é um importante registro local acerca do tema apresentado, tendo em vista a escassez de produção científica sobre a FC.

Palavras chaves: Fibrose cística, Doença genética, Doença pulmonar.

\begin{abstract}
Case report: Patient $01: 33$, since adolescence had dyspnea on exertion, cough and pneumonia. In adulthood, it evolved with worsening of lung function and hypersecretion, being diagnosed with cystic fibrosis by two positive sweat tests. Presented infectious complications, was admitted to perform antibiotic therapy during hospitalization had respiratory failure and shock, and after he presented clinical deterioration and evolved to death. Patient 02: 32, had in childhood cough secretive and dyspnea on exertion. As an adult, the symptoms worsened. In consultation was evaluated and diagnosed with CF through positive test sweat. Follow stable with occasional antibiotics for clinical exacerbations. The family had positive history for the disease, with a brother and paternal aunt deceased with diagnostic and clinical history suggestive, respectively. Discussion: Affirming the genetic character of the CF, described the report of two adult patients and siblings. The disease is directly related to the severity of lung disease. One patient had malnutrition, confirming the severe pancreatic insufficiency described in the literature. Studies say that infertility is common in CF patients, unlike patients in this study, who already have formed offspring. One patient died during the study, confirming the poor prognosis of the disease. The study is configured as important local registry on the subject presented in view of the scarcity of scientific literature on the CF.
\end{abstract}

Key words: Cystic fibrosis, Genetic disease, Pulmonary disease.

\footnotetext{
${ }^{1}$ Unidade de Pronto Atendimento de Icoaraci, Belém do Pará. * E-mail: maytedossantos@hotmail.com

2 Professora Adjunta da Faculdade de Medicina da Universidade Federal do Amapá.
} 


\section{RESUMEN}

Reporte de caso: Paciente 01: 33, ya que la adolescencia tuvo disnea de esfuerzo, tos y neumonía. En la edad adulta, evolucionó con el empeoramiento de la función pulmonar y la hipersecreción, y se le diagnosticó fibrosis quística mediante dos pruebas de sudor positivas. Presentó complicaciones infecciosas, se admitió a realizar antibioticoterapia durante la hospitalización por insuficiencia respiratoria y shock, y después presentó deterioro clínico y evolucionó a la muerte. Paciente 02:32, tuvo secreción de tos en la infancia y disnea de esfuerzo. Como adulto, los síntomas empeoraron. En consulta fue evaluado y diagnosticado con CF a través de sudor test positivo. Siga estable con antibióticos ocasionales para las exacerbaciones clínicas. La familia tuvo una historia positiva de la enfermedad, con un hermano y una tía paterna fallecidos con un diagnóstico y una historia clínica sugestiva, respectivamente. Discusión: Afirmando el carácter genético de la FQ, describió el informe de dos pacientes adultos y hermanos. La enfermedad está directamente relacionada con la gravedad de la enfermedad pulmonar. Un paciente tenía desnutrición, lo que confirma la insuficiencia pancreática grave descrita en la literatura. Los estudios dicen que la infertilidad es común en los pacientes con FQ, a diferencia de los pacientes en este estudio, que ya han formado descendencia. Un paciente murió durante el estudio, lo que confirma el mal pronóstico de la enfermedad. El estudio se configura como registro local importante sobre el tema presentado en vista de la escasez de literatura científica sobre la FQ.

Palabras clave: Fibrosis quística, Enfermedad genética, Enfermedad pulmonar.

\section{INTRODUÇÃO}

Fibrose cística (FC) ou mucoviscidose é uma doença genética autossômica recessiva, ocasionada por mutação no gene que codifica a proteína CRTF, localizado no braço longo do cromossomo 7 (FIRMIDA e LOPES, 2011). Sua repercussão é sistêmica e se caracteriza por aumento da viscosidade das secreções das glândulas exócrinas devido ao transporte defeituoso de cloreto pelas membranas celulares. Tal defeito gera repercussões que comprometem órgãos como pulmão, fígado, pâncreas, testículos, intestinos, glândulas sudoríparas e musculatura esquelética. (PESSOA, 2015).

Apesar de não haver queixa de suor salgado entre os pacientes estudados, os mesmos possuíam prova do suor alteradas. Ambos apresentavam doença pulmonar grave desde a infância e declínio progressivo da função pulmonar com agudizações infecciosas. Além disso, os pacientes apresentavam quadros diarreicos frequentes, estando um deles com desnutrição crônica.

O diagnóstico de FC deve se basear na presença de uma ou mais manifestações clínicas características: doença sinusal ou pulmonar crônica e/ou insuficiência exócrina pancreática crônica e/ou história familiar de FC e/ou teste duplamente positivo de triagem neonatal, associadas à evidência de elevação anormal da concentração de cloro no suor. (REIS e DAMACENO, 1998).

No Brasil, a incidência da FC é estimada em 1:7000 nascimentos, porém essa incidência tem variações de acordo com a miscigenação de cada região (PESSOA, 2015). Já em relatórios de 2014 os números por região foram: região Sudeste com 1690 casos (48\%), região Sul com 741 pacientes (21\%), região Nordeste com 659 casos (19\%), região Centro-Oeste apresentou 199 doentes (6\%) e a região Norte com apenas 152 fibrocísticos (4\%) (GBEFC, 2014).

Há estimativas de que $10 \%$ do total anual de afetados são diagnosticados, o que confere uma impressão errônea de baixa incidência na população brasileira (NETO e NETO, 2008). Em 2001, foi criado o Programa Nacional de Triagem Neonatal (PNTN), que amplia a triagem neonatal no Brasil para quatro doenças (fenilcetonúria, hipotireoidismo congênito, anemia falciforme e fibrose cística) e objetiva atingir $100 \%$ de cobertura dos recém-nascidos vivos. (LEÃO e AGUIAR, 2008).

O grande espectro de apresentação clínica da doença entre pessoas com o mesmo genótipo sugere que, além da grande variação de gravidade produzida pelos efeitos de diferentes mutações e dos polimorfismos intragênicos no gene CFTR. Somando-se a isso alguns fatores ambientais, como infecções bacterianas e aumento do estresse oxidativo, levam ao aumento dos danos pulmonares (CABELLO, 2011). 
Na década de 50 o óbito por FC ocorria em média aos 2 anos de idade, hoje tal desfecho ocorre por volta dos 37 anos. Reconhece-se hoje que a sobrevida do paciente com FC está fortemente relacionada ao grau de disfunção pulmonar e ao seu estado nutricional. (ATHANAZIO, 2017).

Segundo o relatório de 2014 do Grupo Brasileiro de Estudos em Fibrose Cística, na região Norte são nascidos $4 \%$ dos pacientes fibrocísticos do país. Além disso, 3,6\% dos pacientes são atendidos no Norte, no único centro de atendimento existente na região, o Hospital Universitário João de Barros Barreto, localizado no estado do Pará. O Hospital de Clínicas Dr. Alberto Lima é o único local de tratamento e acompanhamento dos pacientes fibrocísticos no Amapá. Este estudo objetiva descrever as características clínicas, de 2 irmãos diagnosticados com fibrose cística na fase adulta. Por ser uma doença de manifestações tão diversas e limitante, se torna imprescindível conhecer o perfil dos pacientes de cada região, afim de que possam ser feitos diagnósticos mais precoces e abordagens cada vez mais integrais e individuais dos portadores de FC.

\section{RELATO DE CASO}

PACIENTE 1: sexo masculino, 33 anos de idade, procedente e domiciliado em Macapá, possui dois filhos. Queixa principal: Cansaço. História da doença atual: relatou que durante sua adolescência, percebeu um cansaço progressivo ao iniciar trabalhos manuais, e frequentemente apresentava resfriados e tosse com chiado no peito. Já adulto, houve piora do cansaço, aumento de secreção pulmonar e episódios repetidos de infecção pulmonar. Iniciou acompanhamento com pneumologista, no qual desde a primeira consulta ambulatorial no Hospital das Clínicas Dr. Alberto Lima, houve a forte suspeita clínica, tendo sido solicitado dois testes do suor e tomografia computadorizada do tórax. Em retorno com exames, foi realizado o diagnostico através de dois testes do suor positivos com FC por apresentar quadro clínico compatível com a doença e dois testes do suor positivos. Antecedentes pessoais: caxumba, hepatite A, varicela na infância, asma e pneumonias de repetição. Nega diabetes e hipertensão arterial. Antecedentes familiares: Um irmão com fibrose cística, o irmão mais velho - já falecido- e tia paterna com história clínica sugestiva de FC. Diabetes e hipertensão no irmão vivo. Mãe diabética e hipertensa. Hábitos de vida: nega etilismo, tabagismo, uso de drogas ilícitas. Negou a prática de atividades físicas. Exame físico: Consciente e orientado no tempo e no espaço, afebril, acianótico, anictérico, com anasarca, emagrecido, palidez cutânea, com taquipnéia em repouso e uso contínuo de oxigênio inalatório, apresenta baqueteamento digital em mãos e pés. Ausculta pulmonar: Murmúrio vesicular presente, bilateralmente, com roncos difusos e crepitações. Ausculta cardíaca: bulhas cardíacas normofonéticas, regulares em 2 tempos, sem sopro. Exame abdominal: doloroso a palpação em flanco esquerdo, sem mais alterações. Índice de massa corporal: $18 \mathrm{~kg} / \mathrm{m}^{2}$

Exames complementares: Teste do suor (06/06/2012) Cloro: 49,1mEq/l (valor diagnóstico: >60mEq/l). Teste do suor (12/06/2012), Cloro: $58,6 \mathrm{mEq} / \mathrm{l}$ (valor diagnóstico: $\geq 60 \mathrm{mEq} / \mathrm{l}$ ). Prova de função pulmonar (22/09/14): Distúrbio ventilatório obstrutivo severo. Prova broncodilatadora positiva. (Capacidade vital forçada (CVF) de 1,48 L (33\% do previsto), volume expiratório forçado no primeiro segundo (VEF1) de 0,65 L (16\% do previsto) e relação VEF1/CVF de 44\%. Tomografia computadorizada de tórax (17/05/16) Bronquiectasias cilíndricas e áreas de faveolamento distribuídas por todo o parênquima pulmonar; Áreas de secreção intraluminal, caracterizando impactação mucóide associada a consolidações notadamente nos lobos médio e inferiores bilateralmente; Espessamento pleuro-apical bilateralmente; Áreas de infiltrado em vidro fosco difusas em ambos os pulmões; Bandas parenquimatosas e áreas de aprisionamento aéreo, de forma difusa, bilateralmente. Sinais de hiperinsuflação pulmonar. (Figura 1)

Evolução: No momento da internação no hospital Dr. Alberto Lima, relatou que há aproximadamente três semanas apresentou, piora da tosse e episódios de epistaxe após espirros, relatou ainda secreção amarelada ao tossir e com raias de sangue, dor torácica à esquerda e febre. 


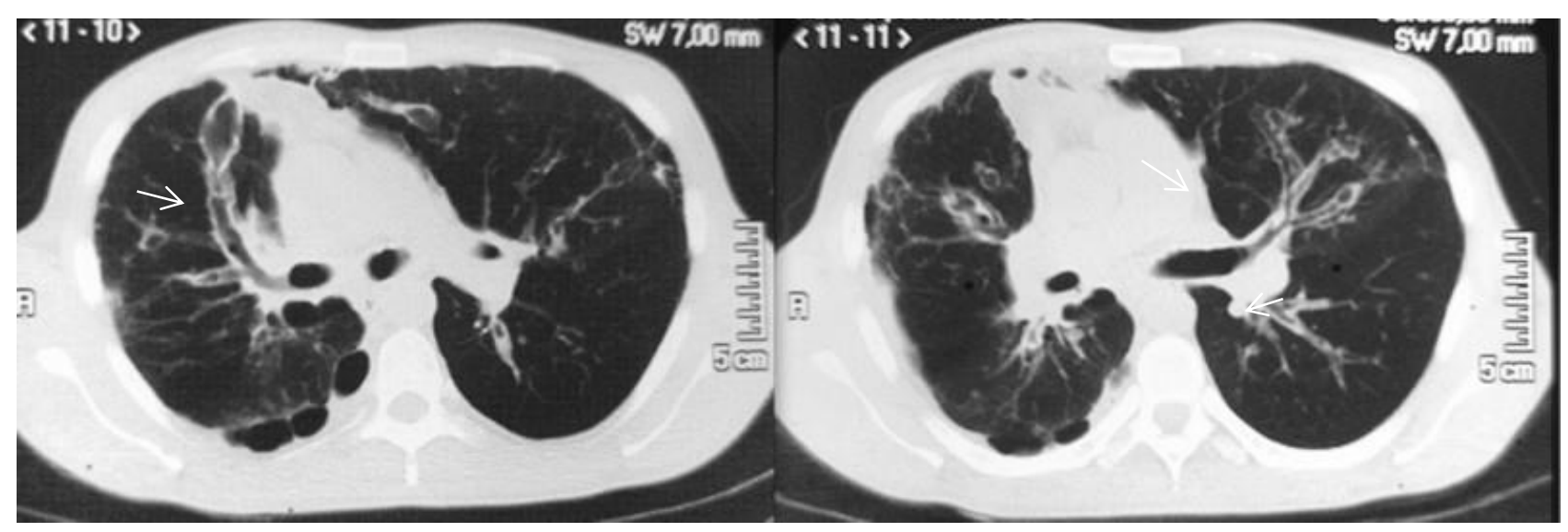

Figura 1: Tomografia computadorizada de tórax do Paciente 1. Áreas de secreção intraluminal, caracterizando impactação mucoide. Fonte: Dados do prontuário do paciente, 2016.

Evolução: No momento da internação no hospital Dr. Alberto Lima, relatou que há aproximadamente três semanas apresentou, piora da tosse e episódios de epistaxe após espirros, relatou ainda secreção amarelada ao tossir e com raias de sangue, dor torácica à esquerda e febre.

Fez uso de levofloxacino por cinco dias em domicílio, porém não apresentou melhora, necessitando internação hospitalar e antibioticoterapia de amplo espectro com teicoplanina $400 \mathrm{mg}$ ao dia em associação com cefepime $2 \mathrm{~g}$ a cada 8 horas durante 14 dias. Posteriormente foi administrado linezolida $600 \mathrm{mg}$ a cada 12 horas durante 14 dias e como ainda apresentou piora da dispneia e febre foi introduzido polimixina B 50mg ao dia. Paralelamente recebeu suporte de fisioterapia respiratória no leito durante toda a internação. $O$ paciente não apresentou disfunção renal ou hepática na enfermaria, onde permaneceu durante 20 dias; porém um declínio progressivo da capacidade pulmonar de oxigenação sanguínea em virtude da infecção por germes não habituais, como Staphylococcus coagulase negativa, Pseudomonas aeruginosa e Achromobacter xylosoxidans. Apresentou insuficiência respiratória e hipotensão, sendo encaminhado para UTI. Durante sua internação apresentou acidose metabólica com hipercapnia e incapacidade progressiva para hematose, além de disfunção endócrina pancreática. Este quadro evolutivo de gravidade irreversível culminou com choque séptico, e parada cardíaca não responsiva a reanimação, sendo declarado o óbito.

PACIENTE 2: Paciente do sexo masculino, 32 anos de idade, procedente e domiciliado em Macapá, três filhos. Queixa principal: Tosse. História da doença atual: paciente quando criança começou a perceber que durante suas brincadeiras, ficava cansado que os colegas, e por isso tinha que dar pausas frequentes em suas atividades. Em sua adolescência passou a apresentar tosse secretiva que vinham em paroxismos. $\mathrm{Na}$ idade adulta iniciou acompanhamento com pneumologista, onde já em sua primeira consulta, observada a história clínica da doença, foram solicitados exames diagnósticos, em seu retorno apresentou as um teste do suor negativo e a tomografia sugestiva de fibrose cística. Com essas informações, associadas à história clínica e aos antecedentes familiares, foi realizado o diagnóstico de fibrose cística. Nunca necessitou de internação hospitalar. Necessitou tratamento com antibiótico frequentemente devido pneumonias de repetição, e, ocasionalmente, apresentou diarreia com restos alimentares.

Antecedentes pessoais: duas internações na infância por pneumonia. Pneumonias de repetição na idade adulta. Refere diabetes e hipertensão. Nunca precisou de internação em idade adulta. Antecedentes familiares: o mesmo apresentado pelo paciente 01. Hábitos: nega tabagismo, etilismo e uso de drogas ilícitas. Negou prática de atividades físicas. Exame físico: Consciente e orientado no tempo e espaço, afebril, acianótico, anictérico, cansaço aos esforços. Apresenta baqueteamento digital em dedos das mãos e pés.Ausculta pulmonar: Murmúrio vesicular presente, bilateralmente, com roncos difusos. Ausculta cardíaca: sem alterações. Exame abdominal: doloroso a palpação em flancos e hipocôndrio direito, sem mais anormalidades. Índice de massa corporal: $28 \mathrm{~kg} / \mathrm{m}^{2}$. 
Exames complementares: Teste do suor (31/10/2013): Sódio: 43,9mEq/l (valor de referência: 10-40 mEq/l) Cloro: $54,8 \mathrm{mEq} / \mathrm{l}$ (valor diagnóstico: $\geq 60 \mathrm{mEq} / \mathrm{l})$. Prova de função pulmonar (11/06/2015): Distúrbio ventilatório obstrutivo severo com prova broncodilatadora positiva (Capacidade vital forçada (CVF) de 2,84 L (55\% do previsto), volume expiratório forçado no primeiro segundo (VEF1) de 1,55 L (36\% do previsto) e relação VEF1/CVF de 55\%). Tomografia computadorizada de tórax (08/10/2015): Bronquiectasias cilíndricas e varicosas com espessamento parietal de predomínio central e superior, bilateralmente. Impactações brônquicas e bronquiolares dispersas e áreas de distúrbio perfusional nos lobos inferiores. (Figura 2).
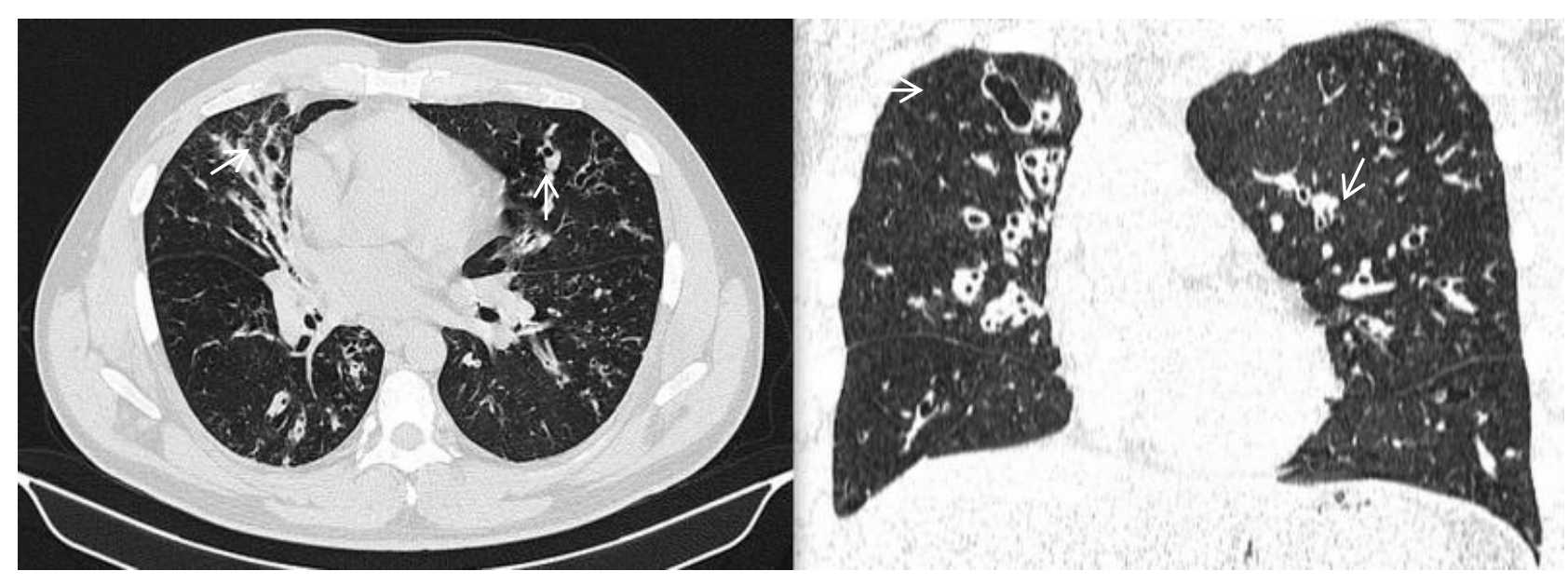

Figura 2: Tomografia computadorizada de tórax do Paciente 2. Bronquiectasias cilíndricas e varicosas. Fonte: Dados do prontuário do paciente, 2016.

Ocasionalmente apresenta aumento de secreção, mudança na coloração da secreção ou piora do cansaço e necessita de antibioticoterapia para a estabilização do quadro. Paciente segue realizando suas atividades diárias normalmente.

Em relação ao tratamento, referiu não utilizar corticóide inalatório ou mucolíticos por dificuldades financeiras. Durante entrevista, declarou não realizar fisioterapia respiratória e acompanhamento psicológico. Paciente também relatou que não realizou exames de cultura de escarro para avaliação de microbiota quando apresentou agudizacões infecciosas.

\section{DISCUSSÃO}

A fibrose cística é uma doença genética rara, multissistêmica, que acomete gravemente a saúde dos pacientes e tem grande potencial letal. Com o maior conhecimento sobre a doença esses pacientes tem chegado a idades cada vez mais avançadas, no entanto, ainda com comorbidades graves e limitação funcional importante. Este cenário demanda a criação de estratégias para o melhor atendimento a estes pacientes. Tais estratégias serão mais eficazes se geradas com base no conhecimento do perfil epidemiológico, clínico e genético destes pacientes.

Levantamentos epidemiológicos concretos sobre este grupo de pacientes são raros sobre a Região Norte do país e não há estudos sobre a FC no estado do Amapá, situação que dificulta tanto o preparo dos profissionais de saúde quanto a geração de e direcionamento adequado de políticas públicas para essa população que, no estado do Amapá, por exemplo, não conta com exames diagnósticos confirmatórios disponíveis na rede pública de saúde.

Os objetivos desse estudo são relatar o caso de dois irmãos adultos com diagnóstico de fibrose cística, descrever a variabilidade clínica dos pacientes e comparar as manifestações clínicas, radiológicas e funcionais dos pacientes com as descritas na literatura. 
Segundo Firmida e Lopes (2011), fibrose cística (FC) é uma doença hereditária, autossômica recessiva, que acomete vários sistemas e possui um grande potencial letal. Um gene defeituoso acarreta disfunção de uma proteína, do mesmo nome, que se situa na membrana apical das células epiteliais de muitos órgãos, e que tem como principal função ser um canal de transporte de cloro. A disfunção da proteína CFTR resulta em uma doença sistêmica variável, e, classicamente, se manifesta como doença pulmonar crônica, má absorção intestinal e concentração de íons cloretos elevada no suor.

Segundo dados estatísticos apresentados pelo Grupo Brasileiro de Fibrose Cística (2014), é possível notar a melhora nos registros sobre a FC, com aumento expressivo de dados coletados quando comparado o ano de 2014 com os anteriores. Devemos admitir a de escassez de levantamentos epidemiológicos concretos em todo o país, onde existe a possibilidade de haver muitos casos não diagnosticados. Supõe- se que escassez de dados na região Norte pode ser devida à baixa densidade demográfica e/ou a não realização de diagnósticos corretos. Esse cenário afeta o conhecimento local sobre a doença e a realização de políticas públicas adequadas para esse grupo de pessoas nesta região.

Firmida e Lopes, em 2011, explicaram que a fibrose cística é uma doença genética do tipo autossômicorecessiva monogênica, onde para expressar a doença o indivíduo precisa ter duas mutações de FC, cada uma herdada de um dos pais. Em nossa pesquisa, três irmãos filhos de um mesmo casal foram afetados, logo, cada pai é um carreador do gene. Existia também uma história familiar paterna para a FC, situação que mostra fortemente o caráter genético que tem a doença.

Como cita Conto (2014), a patologia tem etiologia determinada por mais de 1800 mutações no gene CFTR (Cystic Fibrosis Transmembrane Conductance Regulator), o que justifica a clínica variável e os diferentes graus de perda funcional encontrados na FC. Os pacientes do estudo, por exemplo, diferem em tipo físico, em grau de acometimento sistêmico e em gravidade de doença pulmonar.

Kaktin (2014) diz que, de modo geral, a FC se classifica clinicamente em clássica ou não clássica. A forma clássica, também chamada de típica, é dita a doença em que um ou mais sistemas orgânicos são acometidos, e o paciente apresenta alta dosagem de cloreto no suor ( $\geq 60 \mathrm{mmol} / \mathrm{L}$ ). Contudo em cerca de $2 \%$ dos casos, os pacientes apresentam os critérios diagnósticos clínicos para FC, mas tem um resultado normal ou intermediário na dosagem de cloreto no suor. Nesses casos, diz-se que a doença é não clássica, e o diagnóstico é dependente da análise genética ou da medição de diferença de potencial nasal. Os pacientes desse estudo apresentaram a forma atípica da doença, pois apesar do comprometimento multissistêmico, as dosagens de cloro no suor apresentaram valores limítrofes da normalidade.

A FC pode começar a se manifestar precocemente, ainda no período neonatal, ou tardiamente, onde alguns pacientes permanecem assintomáticos por anos (PRADO, 2011). Apesar de ainda não se identificar fatores que possam deflagrar o início das manifestações clínicas a maioria dos pacientes, ainda crianças, apresentam história de bronquiolite de repetição, síndrome do lactente chiador ou pneumonias de repetição, assim como foi relatado pelos pacientes do estudo.

O paciente 01, em sua última internação teve cultura de escarro positiva para Staphylococcus coagulase negativa, Pseudomonas aeruginosa e Achromobacter xylosoxidans. Os dois últimos microorganismos são comuns em pacientes fibrocísticos, sendo o Achromobacter xylosoxidans um tipo de microorganismo ambiental e raro em qualquer outro grupo de pacientes, o que acorda com os estudos que dizem que os pulmões de pacientes com fibrose cística são uma espécie de nicho para essas e outras bactérias.

Em relação a prova de função respiratória do paciente 01 , verificou-se um declínio quando se comparou dois exames feitos com intervalo de dois anos (VEF1/CVF pré-broncodilatador (pré-BD) $=50 \%$ e após 2 anos, $44 \%$ ), ratificando o que se encontra na literatura a respeito do assunto, porém observou-se melhora da função após uso de broncodilatador (pós-BD) no exame mais recente (VEF1 pré-BD=0,65 I; VEF1 pós-BD=0,84 I). O paciente 02 apresentou melhor função pulmonar que o paciente 01 , compatível com um perfil mais brando de apresentação da doença (CVF pré-BD = 2,84 I; VEF1/CVF pré-BD $=55 \%$ ). No entanto, os dois pacientes apresentaram distúrbios ventilatórios graves. 
Segundo Athanazio (2013), a mortalidade da FC está diretamente associada à insuficiência respiratória devido à infecção crônica. Com exceção das vezes em que tentou-se controlar a exacerbação da doença nos pacientes estudados, a função respiratória sempre esteve decaindo durante a evolução clínica dos mesmos. Por sinal, a perda da função pulmonar para mínima foi fator central na evolução ao óbito do paciente 01 .

Firmida e Lopes (2011) explicam, sobre as glândulas sudoríparas, que ocorre uma anormalidade na homeostase do cloreto de sódio nas glândulas desses pacientes, que então passam a apresentar um alto teor de sal no suor. A principal queixa dos pacientes é o suor salgado, podendo até haver depósito de cristais na pele. Os pacientes do estudo não se queixaram de suor salgado, nem apresentavam cristais depositados na pele.

Segundo os estudos de Espadinha (2010), cerca de 97\% dos homens com FC são inférteis e a explicação anatômica para isso é uma ausência bilateral de vasos deferentes, ou atrofia do epidídimo e vesículas seminais. No entanto, em nosso estudo, foram observados dois raros casos de homens com FC férteis, ambos com prole constituída - o paciente 01 com 2 filhos e o paciente 02 com 3 filhos.

Observamos neste estudo um discrepância entre o estado nutricional dos pacientes analisados. O paciente 01 apresentava desnutrição, com IMC: 18 , e o paciente 02 estava com sobrepeso, IMC: 28 . O estado nutrional do paciente tem uma importante relação com a evolução da doença pulmonar a longo prazo, estando relacionado com a qualidade de vida e a sobrevida desses pacientes. A desnutrição na FC é multifatorial, ocorrendo principalmente por: aumento das necessidades energéticas, devido ao maior esforço respiratório; diminuição da ingesta, causada por anorexia e vômitos; e pelo aumento das perdas por insuficiência pancreática e complicações intestinais, fatores que juntos tem como consequência a perda de massa magra, a depleção da função imunológica, levando à um déficit nutricional crônico (SIMON, 2006).

O Programa Nacional de Triagem Neonatal (PNTN), implementou, a partir de 2001, a investigação para FC no país. No entanto, pacientes que atualmente tem mais que 15 anos, não foram contemplados na triagem do PNTN, e assim como observado neste estudo o diagnóstico será dependente da manifestação da doença, e, portanto, mais tardio.

Os exames de imagem dos pacientes analisados, apresentaram achados como bronquiectasias cilíndricas e varicosas, impactações brônquicas e bronquiolares, áreas de faveolamento, áreas de secreção intraluminal, áreas de infiltrado em vidro fosco, áreas de aprisionamento aéreo e sinais de hiperinsuflação pulmonar, achados ditos típicos por Capone (2011) para pacientes com fibrose cística em fase avançada.

Hoje, apesar da progressão, a expectativa de vida dos fibrocísticos é de aproximadamente de 37 anos, e a idade média ao óbito no Brasil é de 18,9 anos (GBEFC, 2014). Os pacientes analisados estavam na $4^{a}$ década de vida e ultrapassaram a idade média ao óbito, o que corrobora com os dados obtidos na literatura.

\section{REFERENCIAS}

1. ATHANAZIO RA, SILVA FILHO LV, VERGARA AA et al. Grupo de Trabalho das Diretrizes Brasileiras de Diagnóstico e Tratamento da Fibrose Cística. J Bras Pneumol. 2017;43(3):219-245

2. CABELLO GM. Avanços da genética na fibrose cística. Revista Hospital Universitário Pedro Ernesto, 2011; 10(4): 36-451.

3. CONTO C, VIEIRA C, FERNANDES K et al. Prática fisioterapêutica no tratamento da fibrose cística. ABCS health sci, 2014; 39(2): 96-100.

4. ESPADINHA AS. Diagnóstico Laboratorial da Fibrose Cística. Tese (Doutorado em Ciências Farmacêuticas) - Departamento de Química e Farmácia. Universidade do Algarve, Faro, 2010.

5. FIRMIDA MC, LOPES, AJ. Aspectos epidemiológicos da fibrose cística. Revista Hospital Universitário Pedro Ernesto, 2011; 10(4):1222.

6. Grupo Brasileiro de Estudos de Fibrose Cística (GBEFC). Registro Brasileiro de Fibrose Cística (versão provisória). 6.ed. 2014.

7. KATKIN JP. Cystic Fibrosis: Clinical Manifestations and Diagnosis. 2014.

8. LEÃO LL, AGUIAR MJ. Triagem neonatal: o que os pediatras deveriam saber. Jornal de Pediatria, 2008;84(4):80-90.

9. NETO NL, NETO N. Fibrose cística: enfoque multidisciplinar. Hospital Infantil Joana de Gusmão, 2008.

10. PESSOA IL, GUERRA FQ, MENEZES CP et al. Fibrose cística: aspectos genéticos, clínicos e diagnósticos. R Bras Cir e Pesq Clín, 2015;11(4):30-36.

11. PRADO ST. O papel da fisioterapia na fibrose cística. Revista Hospital Universitário Pedro Ernesto, 2011;10(4):118-125.

12. REIS FJ, DAMACENO N. Fibrose cística. Jornal de Pediatria, 1998;74(1):76-94.

13. SIMON MI. Estado nutricional e função pulmonar em pacientes com fibrose cística. Dissertação (Mestrado em Ciências Médicas). Universidade Federal do Rio Grande do Sul, Porto Alegre, 2006; $p 122$. 